$\mathbb{T}$ periodica polytechnica

\author{
Mechanical Engineering \\ $51 / 1(2007) 45551$ \\ doi: 10.3311/pp.me.2007-1.07 \\ web: http://www.pp.bme.hu/me \\ (c) Periodica Polytechnica 2007 \\ RESEARCH ARTICLE
}

\section{Thermal comfort investigation in Libya}

\author{
Adel Akair / László Bánhidi
}

Received 2007-03-14

\begin{abstract}
A thermal comfort field survey has been conducted in three towns from two climatic zones in Libya. Two hundred persons were concerned by this survey. They have been asked in their houses and working places under their normal living conditions once each month during 1 year. The selected sample of buildings has been chosen among free running buildings. Only few office buildings were equipped with heating systems but not with air conditioning systems. The survey results have been processed and correlations between sensations and globe temperatures have been found. The comfort temperatures have been calculated for each location and each month. They have been correlated with the mean outdoor air temperature and with the outdoors running mean temperature. Robust correlations have been found. The description of this survey and the methodology of data analysis are described in details in this paper. The main results are discussed and compared with those of similar surveys conducted in different geographic locations.
\end{abstract}

\section{Keywords}

Adaptive thermal comfort · field survey $\cdot$ free running buildings $\cdot$ Libya climate

\section{Adel Akair}

Department of Building Service Engineering BME, H-1111 Budapest, Múegyetem rkp. 3., Hungary

\section{László Bánhidi}

Department of Materials Science and Engineering BME, H-1111 Budapest, Bertalan L. u. 7., Hungary

e-mail: banhidi@epgep.bme.hu

\section{Introduction}

A control system is maintaining the indoor in most of developed countries, the central heating systems are commonly used in winter. Air temperature at a set value according to thermal comfort standards [1,17] the use of thermal insulation, multiple glazing and controlled ventilation systems are necessary. In the North African countries, the climate is mild, but the needs to heating in winter and cooling in summer are certain, especially in coast areas where the humidity is high. The traditional buildings provided a relatively acceptable thermal comfort in winter and particularly in summer. These buildings are naturally ventilated and have a high thermal capacity. They are equipped with a courtyard; in those houses, adapted shadowing devices and appropriate orientations of the openings facilitate the control of the solar gains. During summer in the night, when the outdoor air is cooler, people enjoy opening the windows and doors, the building is then cooled by natural ventilation and coolness is stored in the building thermal mass for the next day. This traditional way of construction is not any more possible because of its cost and the change of people's standard of life and behaviours; courtyard houses are replaced with flat or terrace houses. The development of "modern" construction was very fast and no care was paid to the thermal quality of the buildings. Most of the recent buildings are not equipped with thermal insulation and their tightness to air is very poor, this is due to the lack of appropriate standards. While the traditional buildings provide an acceptable thermal comfort, the recent buildings are very poor from the thermal point of view, and the thermal comfort is very low. International thermal standards [1,17] are based on human energy balance obtained assuming steady state conditions. These standards are deduced from the experiments done by Fanger [12] in climatic chambers and use the predicted mean vote (PMV) equation to estimate the human mean response to the thermal environment from the knowledge of three thermal variables. Two among them are related to the ambience, they are the air temperature $\left(T_{a}\right)$, the radiant temperature $\left(T_{r}\right)$ or the globe temperature $\left(T_{g}\right)$, the air velocity (va) and the air relative humidity $(\mathrm{RH})$ or vapour pressure $\left(p_{v}\right)$. Two remaining parameters are related to the occupant's adaptability to the local climate; these are the metabolic 
rate $(M)$ and the clothing insulation $\left(I_{c l}\right)$. The steady state conditions are not reflecting the real life conditions particularly in North Africa where the indoor temperature is free running and the control is done manually by the occupant according to his feeling. People are used to adapt themselves to climate using clothing, posture, kind of activity, natural ventilation, etc. An assessment of the thermal comfort level as felt by the building's occupants must be done under real occupation conditions. We achieved some results of studies of some universities in Libya in the dust area, we will conduct further tests in the lab section of the survey results compare with the real lab tests, and we will be obtained in comparison, new research results.

\section{The objectives of this study}

1 To investigate the occupants perception of the degree of comfort in dynamic conditions,

2 To examine the adaptive behaviour of the occupants on the usage of clothing, activity and available climatic controls in modifying the indoor thermal environment,

3 To develop an adaptive comfort model as an alternative to the fixed temperature set point that most of standards adopt. Such model fits better to the Libya context.

\section{Thermal comfort survey}

The usual thermal comfort standards [1. 17] have been established according to the results of experiments held in climatic chambers [12]. During these experiments, the person posture, his activity and his clothing are fixed, thus, the person sensation is taken under steady state conditions. In real conditions, these parameters are never fixed. Moreover, a person changes one or some of these parameters to adapt himself to his climatic conditions and to seasons. In Libya, three different climatic zones have been identified in the country.

Each of these three zones has its own cultural heritage and traditional architecture reflecting its own particular climate. In addition, there are wide seasonal changes in the weather between summer and winter. In summer, midday temperature can exceed $43{ }^{\circ} \mathrm{C}$ in some regions in the south. In winter, temperature can fall down to around $0{ }^{\circ} \mathrm{C}$ in the North Mountains. In the desert, at the country south, the freezing winter nights are also very common. The indoor design temperatures as described by international standards [17], [1], [24] take no account of climatic variations and people adaptive behaviours. Analysis of thermal comfort field studies have shown that indoor comfort temperature as felt by the occupants is function of mean outdoor temperature[14], [2], [20], [10], [11] and [8]. This means that we can relate indoor comfort temperature to climate, region and seasons. For free running buildings and according to different surveys held under different climatic conditions, Humphreys [14] has found that the comfort temperature can be obtained from the mean outdoor temperature with Eq. 1

$$
T_{c}=0.534 T_{o}+11
$$

Auliciems revised Humphreys equation by deleting some fields studies such those with children as the subjects, and adding more information from other studies not included by Humphreys [15, 16]. These revisions increased the database to 53 separate field studies in various climatic zones covering more countries and more climates. After combining the data for naturally ventilated buildings and air-conditioned buildings, the analysis led to an equation involving the outdoors air temperature $\left(T_{o}\right)$ and the indoor air temperature $\left(T_{i}\right)$, this resulting equation is Eq. 2

$$
T_{c}=0.48 T_{i}+0.14+T_{o}+9.22
$$

Auliciems has also proposed a single line for all buildings, which covered the naturally ventilated buildings and airconditioned buildings [5]. This relation is given by Eq. 3

$$
T_{c}=0.31 T_{o}+17.6
$$

Nicol has conducted several surveys under different climatic conditions. In a first survey in Pakistan [21], he has established a relation between comfort temperature and outdoor temperature given by Eq. 4

$$
T_{c}=0.38 T_{o}+17.0
$$

In a second survey in Pakistan [22], he has found a second regression given by Eq. 5

$$
T_{c}=0.36 T_{o}+18.5
$$

Those relations show clearly that the comfort temperature is related to the outdoor temperature and so to the climate. The difference between those relations confirms that there is no universal comfort temperature.

\section{Conduct of the survey and experimental method \\ 4.1 Methodology}

A cross-sectional investigation has been carried out monthly during a complete year in three different towns covering two climatic zones. In each town, 40 persons have been selected 20 among them have been interviewed in their houses and the 20 other persons have been interviewed in their working places. The total number of subjects was 200 persons spread in three cities. Each person was visited 12 times, once in each month of the year.

\subsection{The survey target population}

An equilibrium between males and females has been respected during the selection of the survey subjects; Table 1 gives the subjects three repartition for the different towns.

The subjects have been selected by the researchers, who are in charge of the survey in each town. No more than two different 


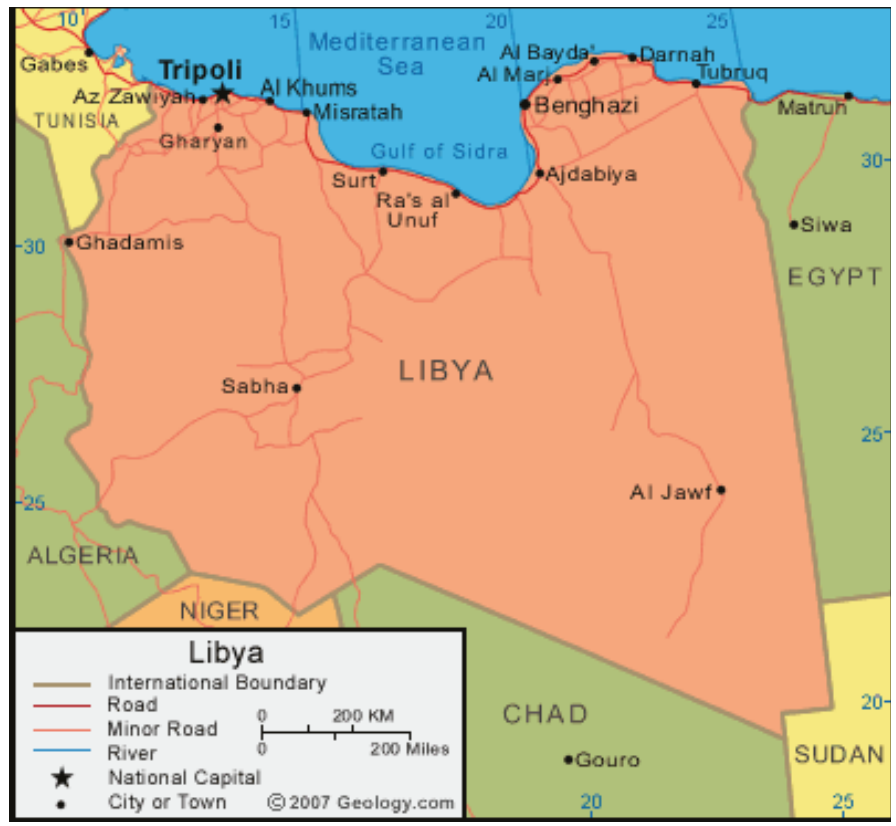

Fig. 1. Show the different three towns in Libya

Tab. 1. Population three repartition

\begin{tabular}{lllll}
\hline & & Women & Males & Total \\
\hline Tripoli & Houses & 12 & 8 & 20 \\
& Offices & 10 & 10 & 20 \\
Gharian & Houses & 13 & 7 & 20 \\
\multirow{4}{*}{ Az Zawiyah } & Offices & 10 & 10 & 20 \\
& Houses & 2 & 18 & 20 \\
& Offices & 2 & 18 & 20 \\
\hline
\end{tabular}

persons were interviewed in the same building; hence, a larger number of different buildings was covered.

\subsection{Experimental method}

Four environmental variables were measured at the moment of the survey: the air temperature $\left(T_{a}\right)$ in $\left({ }^{\circ} \mathrm{C}\right)$, the globe temperature $\left(T_{g}\right)$ in $\left({ }^{\circ} \mathrm{C}\right)$, the relative humidity $(\mathrm{RH})$ in $(\%)$ and the cooling time of a Kata thermometer $(t)$ in (s). All sensors were positioned in the vicinity of the subject along the time during which the survey sheet was being filled.

The subject sensation and preference about which he had to answer in a seven steps scale according to Bedford scale.

Her preference to be warmer or cooler.

His skin moisture.

His feeling and preference about the air velocity.

His activity at the moment of the survey and $30 \mathrm{~min}$ before.

A full description of the conduct of the survey and the results obtained from it is given in Refs. [6, 7].

\subsection{Database}

The responses from the questionnaires were entered in excel for analysis. A database has been built to filter the data according to any fixed criteria. During a preliminary data processing, we eliminated the records for which relevant informations were missing or inconsistent responses are encountered. The air velocity were than calculated from the cooling time of the Kata thermometer, according to the appropriate equation for each thermometer.

\subsubsection{Calculation of the clothing insulation}

Individual clothing articles indicated in the survey responses were converted into their respective thermal insulation value $\left(I_{c}\right)$ in units of Clo as tabulated by Mc Intyre $[18]\left(1 \mathrm{Clo}=0.155 \mathrm{~m}^{2}\right.$ $\mathrm{C} / \mathrm{W}$ ). The overall Clo value for each subject entire clothing ensemble has been calculated using the following equations from Mc Intyre [18] Eqs. 6.a.6.b.

$$
\begin{aligned}
& I_{C l o, \text { men }}=0.113+0.727 \sum I c \\
& I_{\text {Clo,women }}=0.05+0.77 \sum I c
\end{aligned}
$$

\subsubsection{Calculation of the metabolic rate}

The metabolic rate has been calculated from the activity level of each respondent at the moment in which the questionnaire sheet is being filled and his activity level 30 min before according to the following relation Eq. 7]:

$$
M=A_{D u} 58\left(0.71 I_{a c t}^{(0)}+0.3 I_{a c t}^{(-30)}\right)
$$

where $\mathrm{I}_{a c t}^{(0)}$ and $\mathrm{I}_{a c t}^{(-30)}$ are the activity levels at the moment of the survey and respectively $30 \mathrm{~min}$ before the time during which the survey sheet has been filled; $A_{D u}$ is the subject body surface 
area calculated according to Dubois formula as function of the subject weight $(W)$ and height $(H)$ (see Eq. 8 from McIntyre [18])

$$
A_{D u}=0.202 W^{0.425} H^{0.725}
$$

It seems reasonable to expect that the activity at the moment of the survey would be more influential than 30 min earlier. As far as it is known, no other investigators gave indication of appropriate weightings. Rowe [23] conducted a similar survey in which he asked about the activity at the moment of the survey, $10 \mathrm{~min}$ before, $20 \mathrm{~min}$ before, $30 \mathrm{~min}$ before and $60 \mathrm{~min}$ before. He took the following ad hoc weighting factors: $50 \%$ for the 10 min proceeding the moment of the survey, $25 \%$ for the $10 \mathrm{~min}$ before, $15 \%$ for the time corresponding to $30 \mathrm{~min}$ before the survey time and $10 \%$ for the time corresponding to one hour before the survey time.

\subsection{Data summary}

Table 2 summarizes the distribution of the physical measured data by town.

Tab. 2. The distribution of the physical measured data by town.

\begin{tabular}{lllllll}
\hline & $T_{\text {air }}$ & $T_{\text {glo }}$ & Humidity & ET* $^{*}$ & Clo & Met \\
\hline Tripoli & & & & & & \\
Max & 29.5 & 29.2 & 77 & 25.9 & 1.22 & 2 \\
Min & 15 & 15.2 & 34 & 15.6 & 0.07 & 0.7 \\
Average & 23.5 & 24.1 & 56 & 21.2 & 0.55 & 1.23 \\
Gharian & & & & & & \\
Max & 35.5 & 28.1 & 70 & 23.3 & 1.43 & 2 \\
Min & 11.9 & 12.4 & 18 & 14.3 & 0.16 & \\
Average & 21.6 & 21.9 & 52 & 19.6 & 0.62 & 1.19 \\
Az Zawiyah & & & & & & \\
Max & 28.5 & 28.6 & 69 & 23.9 & 1.10 & 1.68 \\
Min & 15.7 & 16.1 & 46 & 9.4 & 0.20 & \\
Average & 21.8 & 22.2 & 57 & 15.1 & 0,56 & 1.12 \\
\hline
\end{tabular}

\section{Behavioural adaptation}

The clothing value, the metabolic rate, the posture and the air velocity indicate the behavioural adaptations. For the case of our study, the posture has not been taken in consideration. The only method that was found in the literature to measure the posture effect is very difficult to conduct in a so large and spread survey. Nicol [20] has conducted in Oxford Brookes University a 2-day survey in which he has shown that the change of posture with temperature causes a reduction of the body effective surface area of about $2 \%$ for each degree rise in temperature. Our survey focused on the evaluation of the clothing insulation and the metabolic rate. The air velocity was used as means to measure the occupant control on the doors and windows opening.

Clothing value is an important behavioural adaptation to achieve thermal comfort at different temperatures. The value of the clothing thermal insulation worn by the survey subjects, we found that a correlation exists between the Clo value and both the outdoor temperature and the indoor globe temperature. Figs. 2a, 2p show how the Clo value varies with the outdoor temperature respectively the indoor globe temperature.

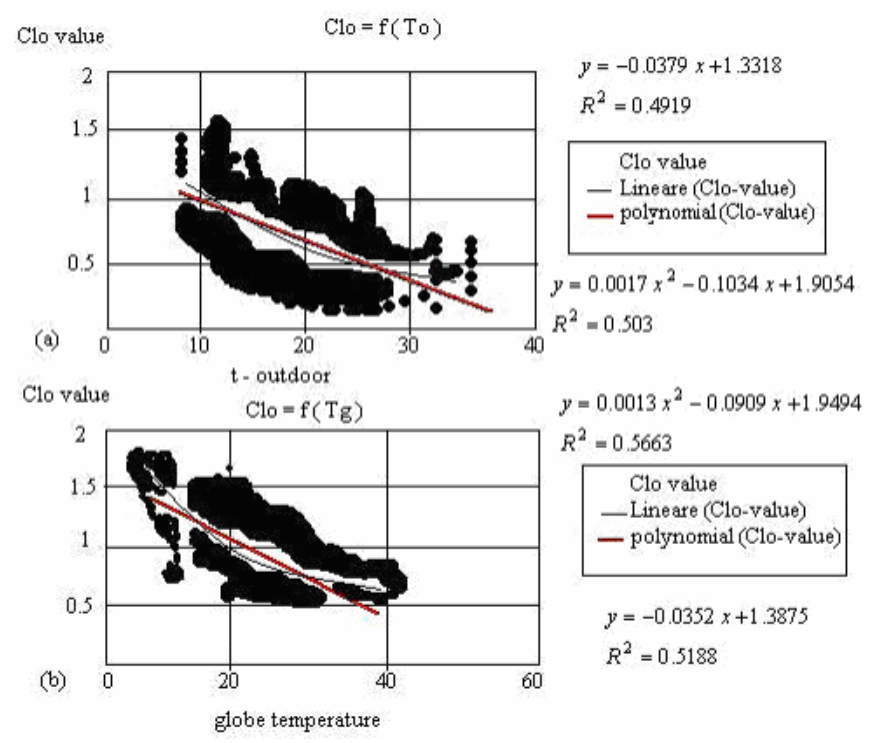

Fig. 2. (a) Correlation of clothing to outdoor temperature (b) Correlation of clothing to globe temperature.

A similar analysis has been led by de Dear [10], he has found the expression found by regression and given by Eq. 9

$$
\text { Clo }=-0.04 T_{o}+1.73
$$

Mui [12] in a similar study has found a very similar relation given by Eq. 10 .

$$
C l o=-0.04 T_{o}+1.76
$$

In our actual study, we found a regression Eq. 14 showing that the correlation between the clothing insulation and the outdoor temperature is very close to de Dear [9] but the clothing overall insulation value in Clo was lower in our case. The constant term in our model is lower than those given in eqs. $(12,13)$. This correlation shows that the Libya population uses lighter clothes, and hence has a higher physiological potential of adaptation to climate change than the populations investigated by de-Dear and Mui.

$$
C l o=-0.0387 T_{o}+1.33
$$

A second order polynomial regression for the same set of data gave Eq. 12 .

$$
C l o=0.0017 T_{o}^{2} \quad-0.1034 T_{o}+1.9
$$

Extrapolation of this equation to very high temperatures (40$50{ }^{\circ} \mathrm{C}$ ), corresponding to desert conditions) shows that the clothing insulation increases. This result seems also realistic according to the behaviour of people living in the desert who wear heavy clothes during the hot summer days to protect themselves 
from the effects of hot air and solar radiation, and to favour the sweating.

The linear regression gave the expression described by Eq. 13.a. while the polynomial regression gave Eq. $13 . \mathrm{b}$

$$
\begin{gathered}
\text { Clo }=-0.0013 T_{g}+1.3875 \\
C l o=0.0013 T_{g}^{2}-0.0909 T_{g}+1.95
\end{gathered}
$$

The metabolic rate versus temperature regression line shows that the regression line is nearly horizontal between 1.3 and 1.2 met independently of the value of the temperature. We can conclude that no significant correlation exists. This result sounds correct because the metabolic rate is mainly related to the nature of job or house activity rather than to the environment or temperature.

\section{Comfort votes and thermal acceptability}

Referring to previous research, the comfort temperature has been linearly related to outdoor temperature. The survey data have been used to generate the comfort temperature as felt by the subjects in their real living conditions, then the comfort temperatures have been correlated to the outdoor temperatures and to running mean temperatures.

\subsection{Thermal acceptability}

The comfort votes of the population have been sorted in ascending order. The votes equal to (-1), (0) and (1) are considered as those who take the operative temperature as acceptable.

For each value of the globe temperature, the total number of the votes and the percentage of the votes that are stating the acceptability have been calculated.

1 For temperatures between 16 and $26.5{ }^{\circ} \mathrm{C}$, more than $80 \%$ are voting acceptable. This result shows that there is a high adaptation potential for a so wide temperature range.

2 The distribution is multi-modal. This result can be explained by the fact that for some values of low and some values of high temperatures, the total number of observations is very small, a unique vote stating acceptability will generate a high percentage for the corresponding value of the temperature. Those side percentages of acceptability made that a probit or logit regression is impossible. A polynomial regression has been tested. Two different equations have been found and their plots are shown in Fig. 3 .

The function represented by an order 4 polynomial fits better the data scatter for the acceptable zone, unfortunately, this function deviates from the data for low and high temperatures, and this is to fit the marginal points caused by the small number of votes that have occurred in these temperatures. This function is also more robust, we can adopt it for lack of a better function as probit and we must pay attention to not use it for globe temperatures lower than $10{ }^{\circ} \mathrm{C}$ or higher than $35^{\circ} \mathrm{C}$.

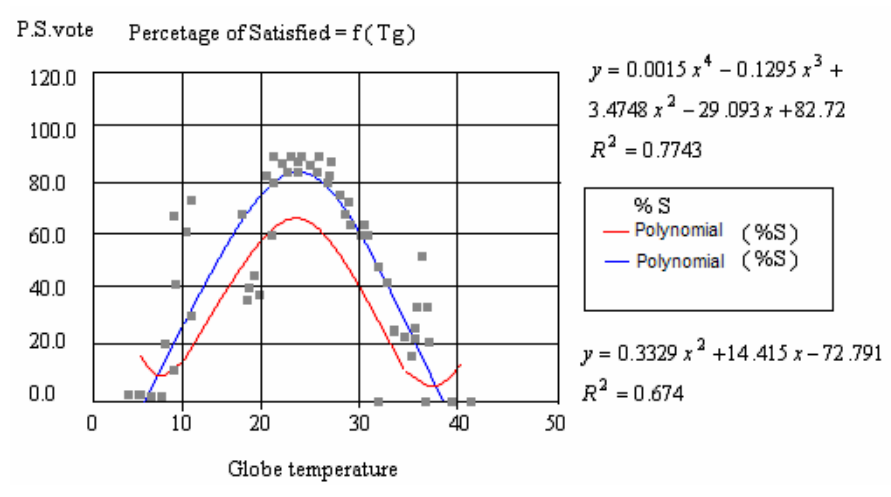

Fig. 3. Acceptable comfort votes as function of the globe temperature.

\subsection{Relation between PMV and sensation}

Using the measured parameters, the PMV has been calculated for each subject according to Fanger [12]. The values of the PMV have been compared to those of comfort votes $(S)$ as described by the subjects. Fig. 4 gives the plot of the PMV as function of the comfort votes. This figure shows that for each value of the sensation (comfort votes), the scatter of the PMV is very large. The regression line does not correspond to the line " $y=x$ ". For the value of $S=-3$, the value of the PMV from the regression is also equal to -3 . For $S=0$, the PMV (from the regression) is equal to -0.87 and for $S=+3$, the PMV (from regression) is equal to 1.28 which is very far from the comfort vote. A polynomial regression seems to be more robust and visually fits better than the linear regression, but also exhibits a scatter from the line " $y=x$ ".

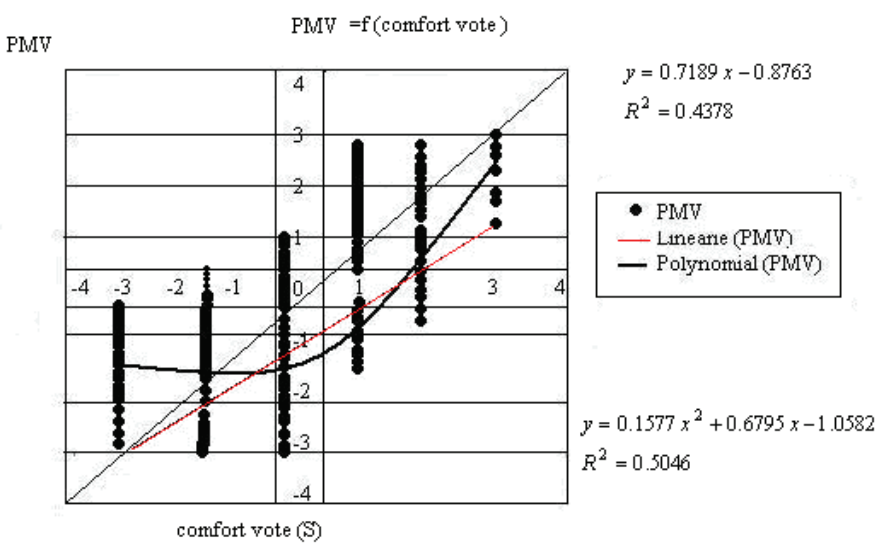

Fig. 4. Calculated PMV as function of comfort votes.

The conclusion that can be inferred from this analysis is that the PMV is a measure of thermal comfort which has been deduced from steady state conditions measurement held in climatic chambers. This measure does not exactly correspond to the real sensation of people particularly in free running buildings in which people are accustomed to adapt themselves to climate.

\section{Development of the adaptive model}

Referring to the previous research, the comfort temperature has been linearly related to outdoors temperature. The survey data have been used to generate the comfort temperature as felt 
by the subjects in their real living conditions, then the comfort temperatures have been correlated to the outdoor temperatures and to the running mean temperatures. The comfort temperature can be defined as the indoor operative temperature for which people can vote comfortable on the Bedford scale (neutral on the ASHRAE scale). For it was observed that some of the points exhibit a bias from the scatter of points. A statistical method called the standard residual method has been used to detect the inconsistent points. Those points which are having a standard residual higher than 2 are automatically eliminated. For each point, the standard residual is calculated as:

$$
R=\frac{e_{i}}{\sigma_{u}}
$$

where $e_{i}$ is the residual calculated as: $e_{i}=Y i$ - $Y i$

$$
\sigma_{u}=\sqrt{\frac{\left(e_{i}\right)^{2}}{N-2}}
$$

$Y_{i}$ is the point ordinate and $Y i$ is the ordinate of the corresponding point on the regression line. According to this method 63 data among 1537 have been removed, which correspond to $4 \%$ of the whole set of data. The analysis will be held using 1474 records.

The temperatures are very close to the comfort temperature, most of the votes are taking the value " $S=0$ " for different values of the temperature, the regression line is nearly horizontal in this case. In such situation, the exact value for the comfort temperature cannot also be inferred and the determination coefficient is very low, what means that the correlation is very weak. Many methods have been adopted to get round this problem:

1 The data can be gathered in a seasonal basis and a thermal comfort temperature can be inferred for each season.

2 The data can be gathered in an annual basis, and an annual thermal comfort temperature can be calculated for each location. This will hide the adaptive behaviour of the occupants along the year.

3 The comfort temperature can be inferred from the Griffiths method [14], which takes an assumed regression slope of $0.33 /{ }^{\circ} \mathrm{C}$ for the relation between comfort votes and temperature.

This method has been adopted and used later by Humphreys and Nicol [16].

4 The comfort temperature can be inferred from the method proposed by Brager and de Dear [8] who have revised the Griffiths method. They made an extensive inspection of the ASHRAE database of thermal comfort field studies and using this data, they suggested an appropriate slope of 0.5 for the relationship between the comfort votes and temperature. This new value of the slope has been adopted by McCartney and Nicol [19] to develop the adaptive control algorithm when they analysed the data for the smart controls and thermal comfort (SCATs) project. In 1978, Humphreys [14] has shown that the outdoor monthly mean outdoor temperature can be used as an appropriate outdoor temperature index. Later studies from Nicol and Humphreys [15, 20] have shown that an exponentially weighted mean outdoor temperature can give more results that are accurate. This index has been called the "running mean temperature" and it calculates a weightedmean from the last day and the previous days with decreasing weighing factors. The expression of the running mean temperature is given by Eq. 17

$$
T R M^{(n)}=C T R M^{(n-1)}+(1-C) T M O^{(n-1)}
$$

where $\operatorname{TRM}^{(n)}$ is the running mean temperature for the actual day; $\operatorname{TRM}^{(n-1)}$ is the running mean temperature 1 day before; $\mathrm{TMO}^{(n-1)}$ is the mean outdoor temperature 1 day before; $C$ is a constant, its value is between 0 and 1 and defines the quickening response of the running mean to changes in the outdoor temperature. A value close to 0 gives a running mean temperature close to yesterday's mean outdoor temperature and a value close to 1 gives a running mean temperature equal to the average value of the last days. This running mean temperature is similar to half-life decay calculations in nuclear physics.

\section{Data analysis and results}

Referring to McCartney and Nicol [19], the running mean temperature was calculated with a coefficient $C=0.8$. The Griffiths comfort temperatures have been correlated to the daily running mean temperatures. The resulting correlation is given by the expression in Eq. 17

$$
T_{c-\text { Griffiths }}=0.532 T R M+11.56\left(R^{2}=0.6262\right)
$$

This result is very close to the correlation between comfort temperature and mean outdoor temperature, but has a slightly higher determination coefficient. Compared to the results of McCartney and Nicol [19], this equation shows that the Libya population is having a higher adaptation capacity than the average European population that was involved in the SCATs project. This difference can be explained by the fact that the SCATs project has been held in air-conditioned buildings while the Libya survey covered only naturally ventilated buildings.

The correlation is very close to the one found by Humphreys in [14], and does not justify the use of the running mean temperature because it was very close to the one correlated to the outdoor temperature. The determination coefficient found for the running mean temperature regression was $35 \%$ lower than that found for the mean outdoor temperature regression.

\section{Conclusion}

Building standards have been based on fixed comfort temperatures found from tests held in climatic chambers. Those stan- 
dards assume that the indoor temperature is fixed to a set value and controlled by heating and air conditioning systems. In Libya and all North African countries, the heating and air conditioning systems, in case they exist, are not used continuously. Thus, the indoor temperature is fluctuating. The thermal sensation of the building occupants is the only controller of the ventilation, the heating or the cooling of the building. Unlike the conventional thermal regulations, which are based on energy consumption, the special feature of the future Libya thermal regulation is related to the fact that it must ensure a minimum level of thermal comfort when the building is free running without any heating or cooling system. The comfort temperature can be correlated to the monthly mean outdoor temperature. Such concept can be used to design comfortable buildings. The comparison between the comfort temperature and the maximum and minimum outdoors temperatures can help designer to judge whether passiveheating and cooling techniques are appropriate for the climate under consideration. The relationship between the indoor comfort temperature and the range of outdoor temperatures shows whether for example night ventilation can be or not a way to keep the building cool in summer and help the designer to select the appropriate thermal capacity for the building. The study suggests that in Libya, the thermal comfort temperature can be calculated from one of the expressions:

$$
\begin{gathered}
T_{c-\text { Griffiths }}=0.518 T_{o-A v g}+10.35, \\
T_{c-\text { Brager }}=0.680 T_{o-A v g}+6.88
\end{gathered}
$$

where $T_{c-\text { Griffiths }}\left({ }^{\circ} \mathrm{C}\right)$ is the comfort temperature calculated using the Griffiths method, $T_{c-B r a g e r}\left({ }^{\circ} \mathrm{C}\right)$ is the comfort temperature found according to de Dear and Brager Method, $T_{o-A v g}$ $\left({ }^{\circ} \mathrm{C}\right)$ is the monthly mean outdoor temperature. The correlations found in the case of our study are in good agreement with those found in the literature particularly the one found by Humphreys. For buildings equipped with heating and air conditioning systems, a variable indoor temperature has to be taken according to the comfort temperature calculated from the above equation. This is in agreement with the common way people used to run their heating or cooling systems. Such method of running will allow an important energy saving compared with the existing standards.

\section{References}

1 Thermal environmental conditions for human occupancy, American Society of Heating Refrigeration and Air Conditioning Engineers, Atlanta, GA, USA, 1992. ASHRAE: Standard 55.

2 Auliciems A, De Dear R, Air conditioning in Australia. I. Human factors, Architectural Science Review 29 (1978), 67-75.

3 Auliciems A, Towards a psychophisiological model of thermal perception, International Journal of Biometeorology 13 (1981), 147-162.

4 _ Psycho-physiological criteria for global zones of building design, Proceedings of the Ninth International Society of Biometeorology Conference Stuttgart, Hohenheim, 1983.

5 Auliciems A, De Dear R, Air conditioning in Australia: human thermal factors, Architectural Science Review 29 (1978), 67-75.
6 Bouden C, Ghrab-Morcos N, Nicol J F, Humphreys N, A thermal comfort survey in Tunisia, Proceedings of the Second European Conference on Energy Performance and Indoor Climate in Buildings, 1998, pp. 491- 496.

7 Bouden C, Ghrab-Morcos N, Le comfort thermique dans les bâtiments tunisiens: Résultats d'une enquête (1999).

8 Brager G S, De Dear R, Developing an adaptive model of thermal comfort and adaptation, ASHRAE Technical Data Bulletin 14 (1998), no. 1.

9 De Dear R, Schiller B G, Cooper D, Developing an adaptive model of thermal comfort and preference, Vol. 104, 1988. SF-98-7-3: 4106, RP 884.

10 De Dear R, Auliciems A, A field study of occupant comfort and office environments in hot-humid climate, 1993. Final report ASHRAE RP-702.

11 De Dear R, Brager G S, Towards an adaptive model of thermal comfort and preference, 1998.

12 Fanger P O, Thermal Comfort, Danish Technical Press, Copenhagen, 1970.

13 Griffiths I, Thermal comfort studies in buildings with passive solar features: field studies report to commission of the European Community, 1990. ENS 35909, UK.

14 Humphreys MA, Outdoor temperatures and comfort indoors, Building Research and Practice 6 (1978), no. 2, 92-105.

15 Humphreys MA, Nicol J F, Adaptive Temperature Guidelines for UK Office Temperatures, E \& F Spon, London, UK, 1995. Standard for Thermal Comfort: Indoor Air Temperature Standards for the 21st Century.

16 Humphreys MA, Nicol JF, Outdoor temperature and indoor thermal comfort: rising the precision on the relationship for the 1998 ASHRAE database of fields studies, 2000.

17 ISO, INTERNATIOAL STANDARD 7730, Moderate Thermal Environments: Determination of PMV and PPD Indices and Specification of the Conditions for Thermal Comfort, Geneva, 1994.

18 Mc Intyer DA, Indoor Climate, Applied Science Publisher Ltd., London, 1980.

19 Mc Cartney KJ, Nicol JF, Developing an adaptive control algorithm for Europe, Energy and Buildings 34 (2002), 623-635.

20 Nicol JF, Raja IA, Thermal comfort and posture. Exploratory studies in the nature of adaptive thermal comfort, Oxford Brookes University, School of Architecture, 1996.

21 Nicol JF, Thermal comfort and temperature standards in Pakistan, Standards for Thermal Comfort-Indoor Air Temperature Standards for the 21st Century, 1995, pp. $149-157$.

22 Nicol JF, Raja IA, Alauddin A, Jamy NG, Climatic variations on comfortable temperature: the Pakistan projects, Energy and Buildings 30 (1999), 261-279.

23 Rowe DM, Activity rates and thermal comfort of office occupants in Sydney, Journal of Thermal Biology 26 (2001), 415 - 418.

24 CR1752, Ventilation building-Design criteria for the indoor environment, 1998. 